\title{
MONITORING OF A MULTI FUNCTIONAL SUBMERGED GEOTEXTILE REEF BREAKWATER
}

\author{
L.Angus Jackson ${ }^{1}$, Rodger Tomlinson ${ }^{2}$, John McGrath ${ }^{3}$, and Ian Turner ${ }^{4}$
}

\begin{abstract}
A large reef has been constructed offshore from Narrowneck on the Gold Coast, Queensland, Australia. The reef provides a submerged, low visual impact, coastal control point to stabilize the nourished northern Gold Coast beaches. As the reef is in a popular tourist and surfing area, it has also been designed and constructed to enhance recreational amenity. For safety and cost efficiency, the reef has been constructed of very large sand filled geotextile units. Experience with the design and construction of such structures is limited and the inclusion of improved surfing as secondary design criteria increases the complexity. To facilitate evaluation and modifications to the reef there is a comprehensive monitoring program, which includes the use of ARGUS video imagery to assess the changes in the shoreline related to wave conditions at the wave rider buoy nearby. Divers are studying the physical performance of the sand filled geotextile containers, as well as the extent and diversity of the marine ecosystem which has exceeded expectations. There have been a number of storm wave events during the monitoring period. The data obtained from the monitoring is being used to modify the long term Narrowneck reef shape, and to design other proposed reefs in the area.
\end{abstract}

\section{INTRODUCTION}

The Gold Coast is located on the east coast of Australia and its economy relies on preservation of its sandy surfing beaches. The Northern Gold Coast Beach Protection Strategy was implemented by Gold Coast City Council to widen and protect the beaches in the vicinity of Surfers Paradise at the northern end of the coastal tourist strip. The

1 Principal Engineer, International Coastal Management, PO Box 7196 Gold Coast Mail Centre, Australia 9726. jackson@onthenet.com.au

2 Professor / Director, Griffith University Centre for Coastal Management, PMB 50 Gold Coast Mail Centre Australia 9726

3 Coastal Engineer - Gold Coast City Council, PO Box 5042, Gold Coast Mail Centre Australia 9726

4 Senior Research Fellow, Water Research Laboratory, School of Civil and Environmental Engineering, University of New South Wales, King St, Many Vale, NSW 2093, Australia. ian.turner@unsw.du.au 
strategy includes construction of a large submerged reef type structure [Jackson et al, 1997] at Narrowneck, just north of Surfers Paradise. The primary purpose of the reef structure is to provide a coastal control point to stabilize the nourished beaches, but it has also been designed to enhance the recreational amenity including surfing, swimming, diving and fishing opportunities and providing aquatic habitat. For safety and cost efficiency, the reef has been constructed of very large geotextile containers ranging from 3 to $4.5 \mathrm{~m}$ diameter by $20 \mathrm{~m}$ long, which were filled with sand in a split hull hopper dredge on site, and dropped onto the nearshore seabed (Photo 1) at the outer side of the surf zone. Experience with design and construction of such structures is limited and the inclusion of improved surfing as a secondary design criteria increased the complexity.

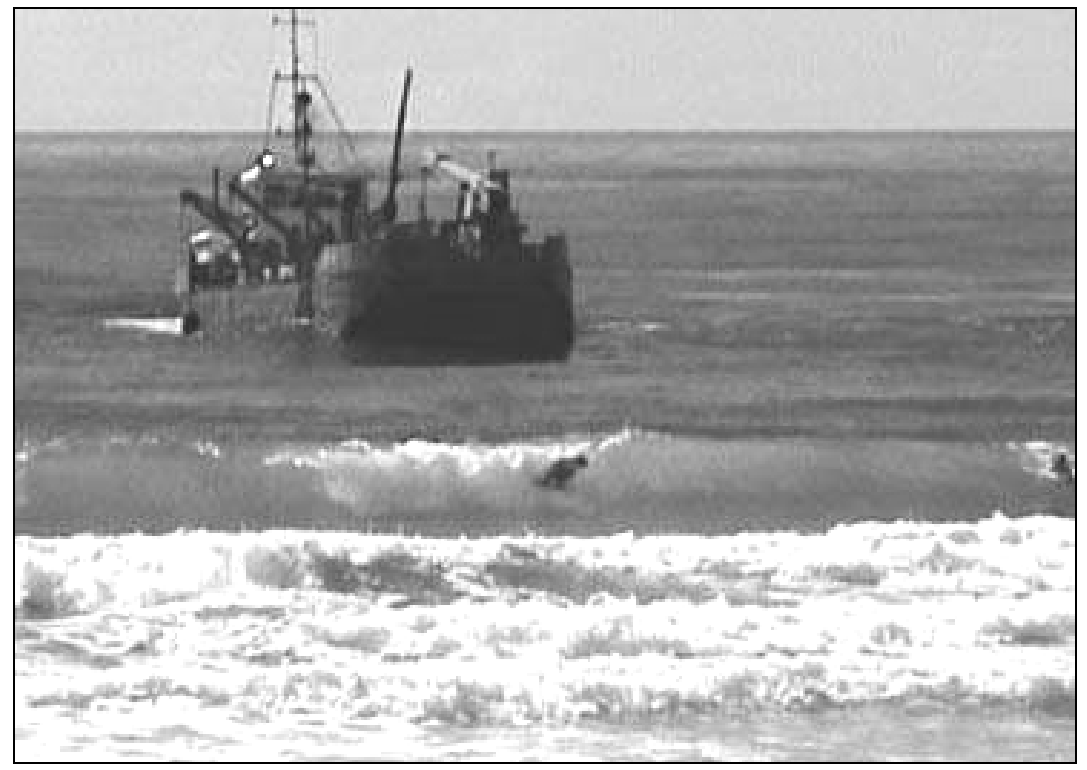

Photo 1. Dredge placing "sand bags" near surfers

A large number of detailed impact assessment studies, including a range of modelling studies, were carried out during the design and approval stages (International Coastal Management 1998). As expected, there were a number of conflicting recommendations from the studies, and it was accepted from experience by the Client and Project Engineers that the modelling results could only provide average results for a limited number of case, and could not fully represent the wide variability of wave, profile and sediment supply conditions that occur at the site. Thus, an extensive monitoring programme (Walsh et al 1999) was implemented to provide data to evaluate performance of the reef to facilitate modifications to the reef and the design of future reefs in the Gold Coast area. In particular, there was considerable concern that the very shallow reef crest height proposed to maximise surfing potential would create unsafe wave breaking and current for the majority of surfers so the design crest height was reduced by $0.5 \mathrm{~m}$ initially. By necessity, reef construction commenced after nourishment on the large storm bar that had been formed by storms combined with the large-scale 
beach and nearshore nourishment. The storm bar was expected to move shoreward resulting in short-term settlement of up to about $1.5 \mathrm{~m}$ as the cost and risk of using scour mattresses was excessive. This settlement provided an opportunity to monitor and evaluate the effect of crest height before a post-construction top up was undertaken.

As such large containers had not been filled and placed underwater to tight specifications previously, an integrated $R \& D$ program for the design, manufacture and accurate placement of large sand filled geotextile containers was undertaken by the contractors, McQuade Marine and Soil Filters Australia.

Construction was commenced in May 1999, and extensive monitoring of individual units and the total structure since this time has been carried out to determine the behaviour of the individual units and impacts of the structure on the beach system. The seabed movements since commencement have resulted in lowering of the structure by up to $2 \mathrm{~m}$, and this has provided data on the effect of crest height on erosion protection, safety and surfing. Wave height data is available from a wave buoy operated by the State Environmental Protection Agency near the site. Monitoring has included: -

- Video “ARGUS" imaging using multiple cameras

- Hydrographic and beach surveys

- Dive inspections

- Aerial oblique photography

- Surf parameter observations

- Pressure sensors in, and on, individual units

\section{SITE CONDITIONS}

The Narrowneck reef is constructed on an open sandy coast, in an area with an average $\mathrm{Hs}=\sim 1 \mathrm{~m}$, and an average longshore transport rate of $\sim 500 \mathrm{~m}^{3} / \mathrm{yr}$. The maximum tidal range is $\sim 2 \mathrm{~m}$. Since monitoring commenced in 1999, there have been 13 storm wave events with $\mathrm{Hm}>5 \mathrm{~m}$ to $31^{\text {st }}$ July 2002. Prior to construction the beach at Narrowneck was narrow, and erosion back to the boulder wall occurred regularly (Photo 2). Since nourishment and reef construction a wide beach has been maintained (Photo 3). 


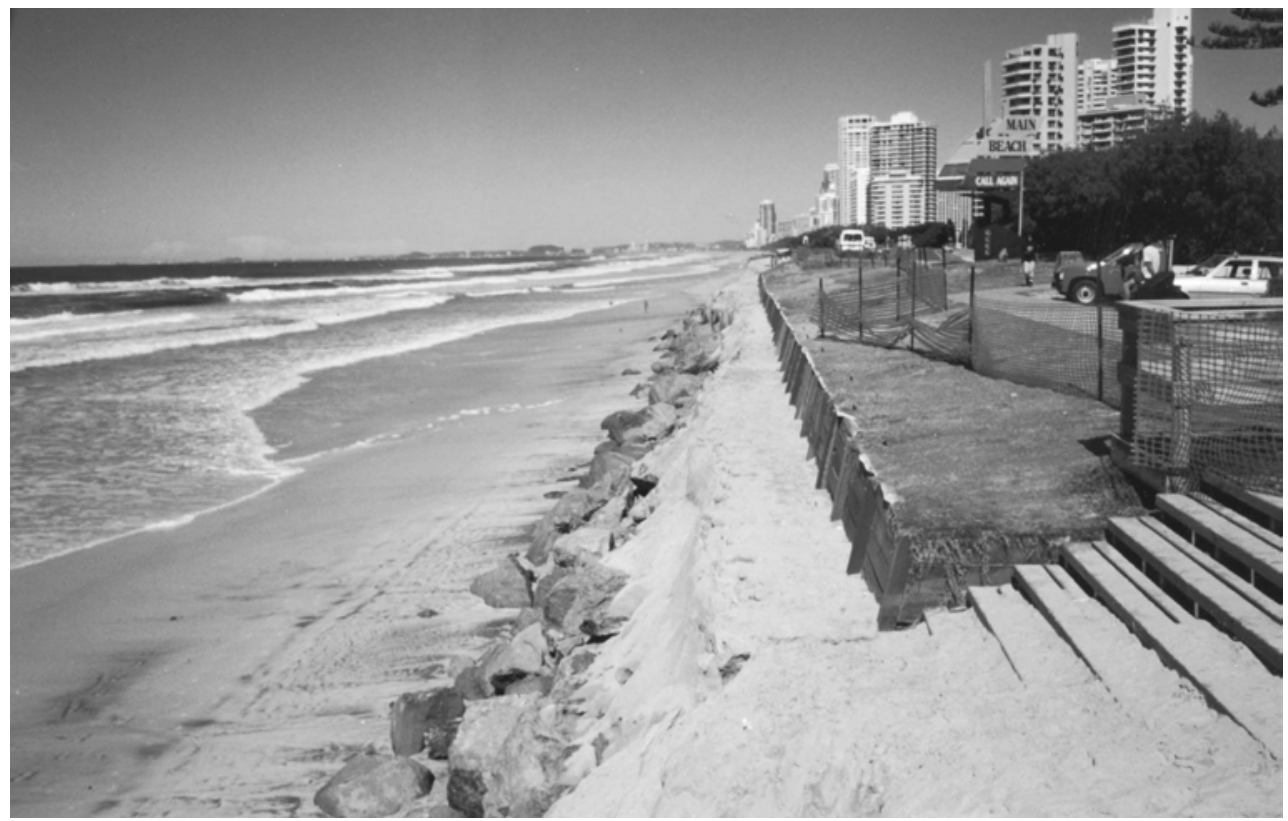

Photo 2. Narrowneck 1996

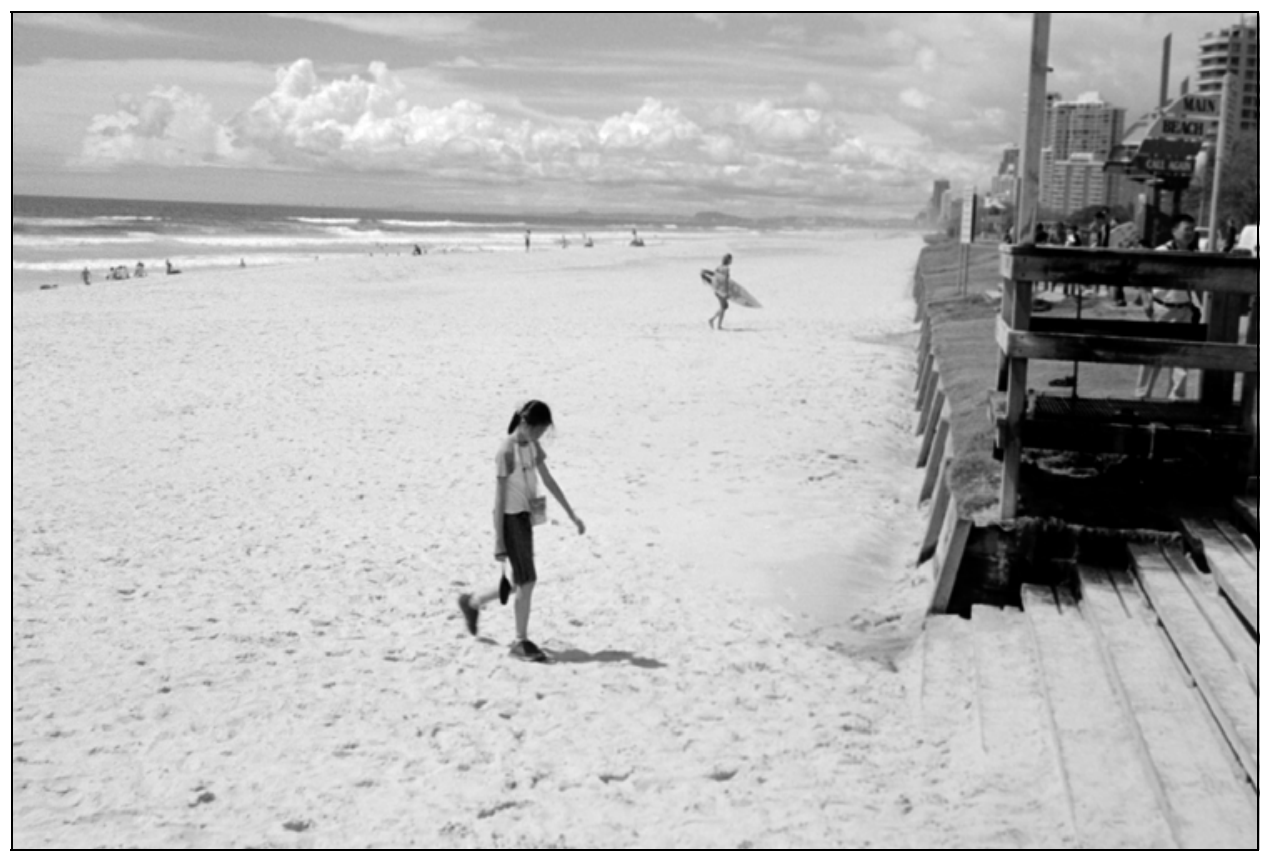

Photo 3. Narrowneck 2002

\section{MONITORING}

Hydrographic and Beach Surveys

At the start of the project there was over 30 years of bathymetric survey data available for this area. The monitoring included regional and site surveys by Council's hydrographic surveyors of the reef during, and after, construction. The location and height of each exposed container was surveyed using a number of accurate hydrographic 
survey techniques including sonar, and direct measurements with a survey staff and "total station". The surveys have shown a widening of the beach and displacement of the barred profile seaward. The survey of the reef and individual containers showed changes in the reef shape due to a number of factors: -

- Initial settlement: A series of controlled surveys were carried out on a selected $3 \mathrm{~m}$ diameter $\mathrm{x} 20 \mathrm{~m}$ long "unit" [ $\mathrm{N} 403]$ to measure the short-term initial settlement. The surveyed settlement of the centre top of the unit in the first 24 hours was $0.1 \mathrm{~m}$. Little scour occurs with permeable large sand filled geotextile containers, and there was no obvious scour so it is likely that this was all initial settlement. As the survey was carried out several hours after dropping, some settlement is likely to have occurred in that time. Thus, the estimation of initial settlement for a $3 \mathrm{~m}$ diameter unit is $0.1 \mathrm{~m}$ to $0.2 \mathrm{~m}$. As echo-sounder survey for this type of work even in calm conditions is restricted to $+/-0.2 \mathrm{~m}$ vertical accuracy and worse in less perfect conditions, a staff was used where possible. However, even with a survey staff errors of at least $+/-0.1 \mathrm{~m}$ vertically were possible.

- Lowering of the units due to gross seabed changes: Narrowneck has been a good example of seabed changes that have affected a flexible structure. In the first 6 months of construction, surveys showed a deepening of the seabed by $2.75 \mathrm{~m}$ adjacent to the shoreward end of the reef. A top up of the north section of the reef was completed in November 2001 with the target crest height lowered to $\mathrm{RL}-2.0 \mathrm{~m}$ AHD mainly for safety reasons.

\section{Video Imaging}

As bathymetric surveys are costly and only capture the bathymetry at discrete intervals, a major component of the monitoring program has been the use of video imagery to assess the changes in the shoreline, as well as wave breaking frequency and surfability [Turner et al., 2000]. This monitoring is being carried out by the Water Research Laboratory at the University of NSW using an ARGUS coastal imaging system [Holman et al., 1993]. This automated monitoring system is used to obtain hourly images from four cameras that combine to provide continuous coverage of 4.5 $\mathrm{km}$ of the coast. Digital image processing techniques are then applied on a routine (daily to weekly) basis to extract a range of quantitative information from the growing image database. The photos provide oblique and rectified images and updated photos are placed on the web at hourly intervals. Photo 4 shows an image looking north to the reef from camera 4.

Based upon the results of weekly digital shoreline mapping and analysis completed for the 3.5 year period to July 2002, it is observed that along the $4500 \mathrm{~m}$ study region beach width changes of typically $60 \mathrm{~m}-80 \mathrm{~m}$ were measured within the central region of the study area, coinciding with the focus of the sand nourishment effort during 19992000. Total beach width changes of $40 \mathrm{~m}-50 \mathrm{~m}$ were more typical to the north and south. A general trend of increasing beach width was apparent during the initial 18 months of monitoring, clearly indicating the dominant effect of nourishment during this 
period. In contrast, during the period $18-24$ months, a general erosion trend occurred. The monitoring period February - July 2001 was characterised by a series of storms that resulted in the net recession of northern Gold Coast beaches. From August 2001 to January 2002 a distinct trend of beach recovery at all locations alongshore was observed. By January 2002 the beach had recovered to the extent that beach widths were sufficiently regained to match the conditions that were measured 12 months previously in January 2001. During the latest 6 month monitoring period February July 2002 a modest net erosional trend was recorded. As a generalisation, the beach at the end of the 36 month period to July 2002 was intermediate between the initial (unnourished) condition in August 1999, and the most accreted states as observed in January 2001 and January 2002

From the video imaging, it was concluded that 3.5 years after sand nourishment commenced at the northern Gold Coast in February 1999, and 2 years after the nourishment program was completed in mid 2000 , an additional $20-30 \mathrm{~m}$ of beach has been achieved along approximately $2 \mathrm{~km}$ of the coastline, relative to the adjacent unnourished beaches to the north and south. The unnourished beaches have accreted some $10-20 \mathrm{~m}$ during this time, with the net result that the nourished beach at Surfers Paradise is some $30-50 \mathrm{~m}$ wider since mid 1999 . In the vicinity of the reef, the net impact of the structure during the first complete 12 month seasonal cycle to January 2002 was to promote additional accretion of the updrift southern beach by up to $25 \mathrm{~m}$ for a distance of 450 alongshore, and $10 \mathrm{~m}$ of net beach accretion for a distance of 400 $\mathrm{m}$ on the down-drift northern side of the reef. During the most recent 6 month monitoring February - July 2002 a modest net erosion trend along the entire $4.5 \mathrm{~km}$ study area was observed. However a decreased rate of net shoreline recession was measured in the lee of the reef during erosion events, with a salient-like feature maintained in this localised region (Figure 1). 
Proceedings of the $28^{\text {th }}$ International Conference on Coastal Engineering 7-12 $2^{\text {th }}$ July 2002 Cardiff, Wales

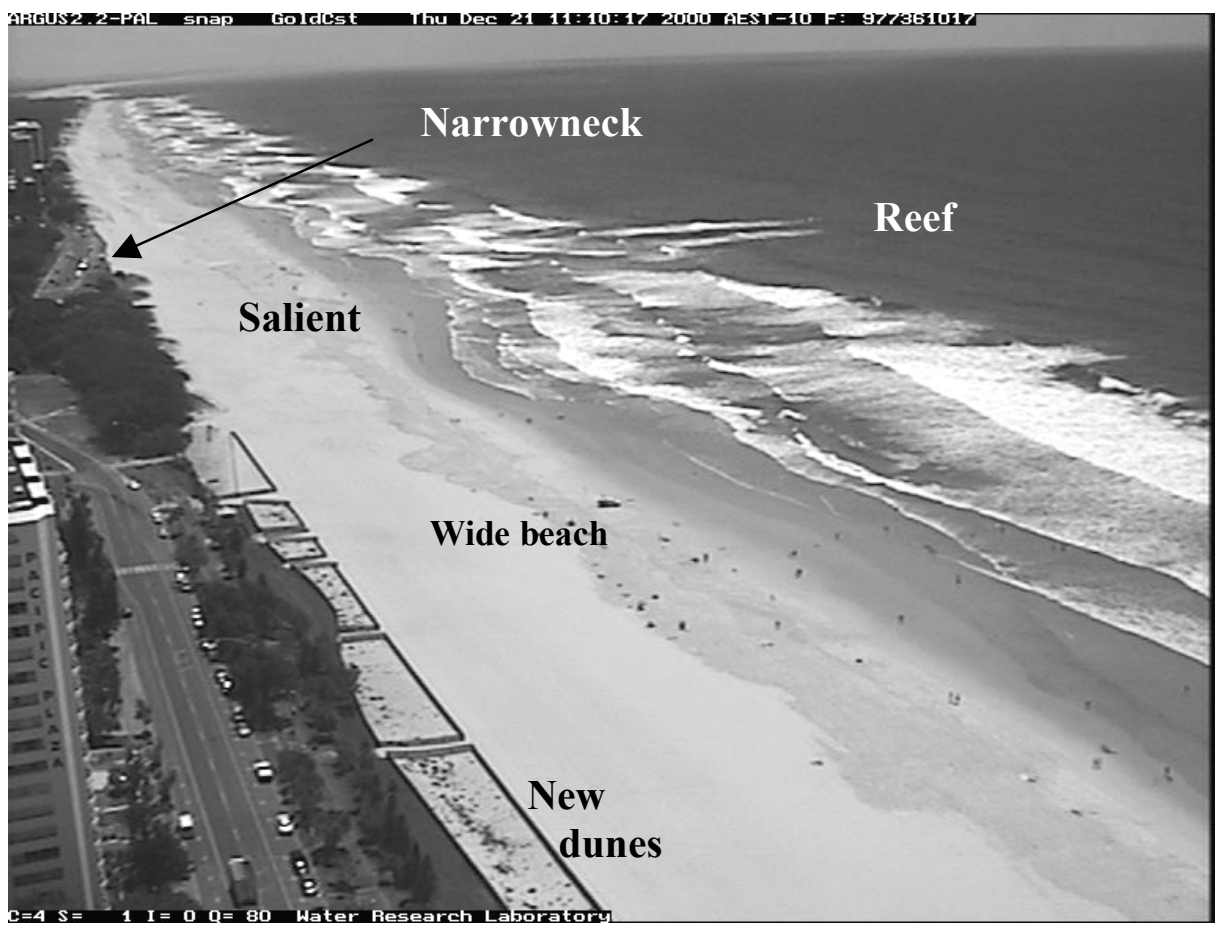

Photo 4. Image from Camera 4

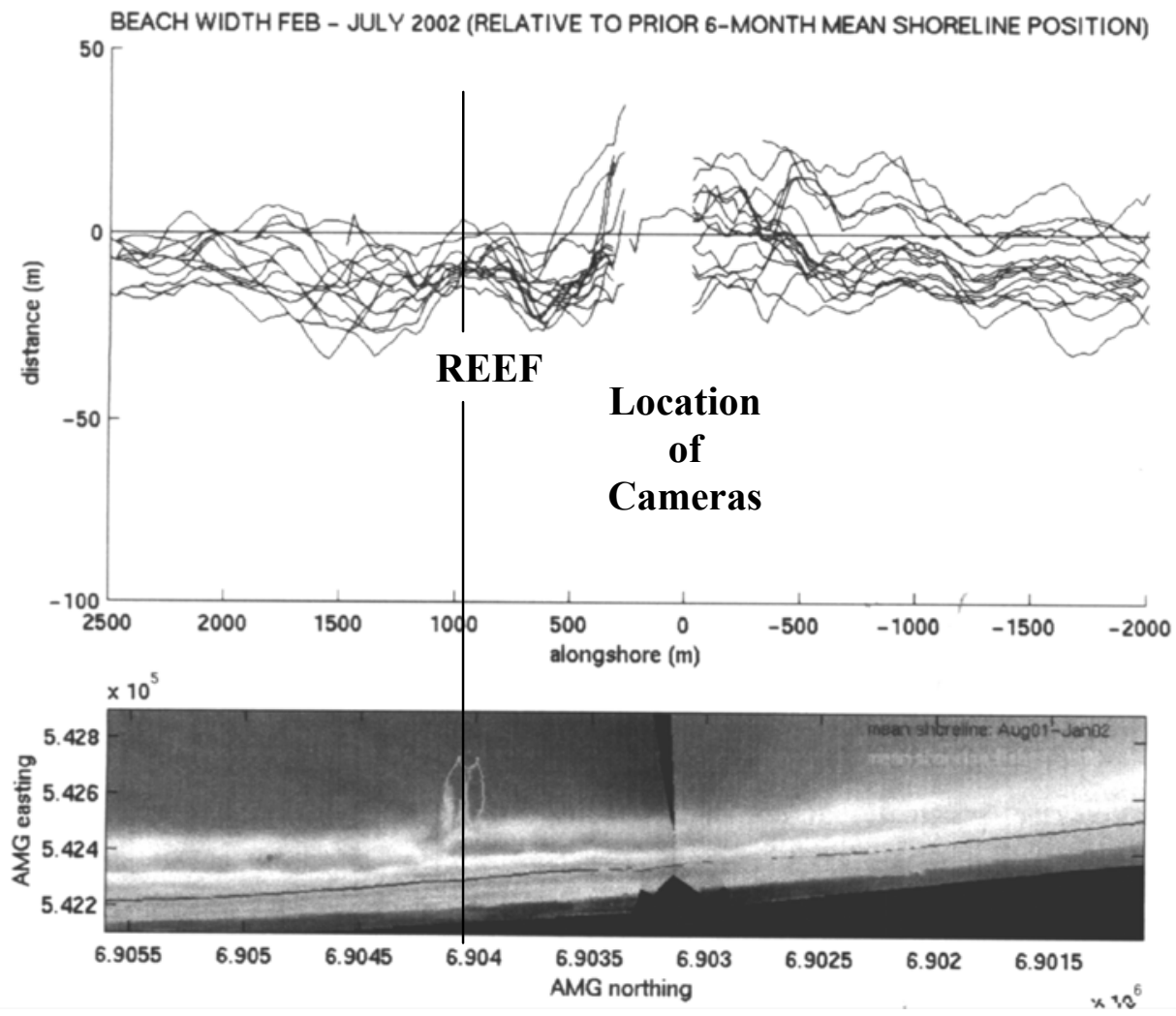


Proceedings of the $28^{\text {th }}$ International Conference on Coastal Engineering

7-12 $2^{\text {th }}$ July 2002 Cardiff, Wales

\section{Figure 1. Beach width changes}

\section{Dive Inspections}

The underwater monitoring has been facilitated by each sand filled geotextile unit being numbered and tagged so its condition, location and height can be monitored. Underwater inspections and photographs are monitoring the condition of each accessible container. In addition, samples of geotextile are being collected and tested to determine any long-term changes, durability and the impact of marine plants on the geotextile. Kelp and other soft flora attach quickly to the geotextile, and the extent and diversity of the marine habitat formed has exceeded initial predictions. As well as attracting surfers, the reef has become very popular with fishermen, scuba divers and skin divers (often with spears). Photographs and videos are being taken of the marine flora and fauna for identification as a postgraduate research project. A preliminary list is shown in Table 1.

It is observed that there is little turbulence and scour around the geotextile units as is normal with rock. Divers took measurements of the settlement of individual units and it is estimated that settlement into the seabed is only $200-300 \mathrm{~mm}$ for a $3 \mathrm{~m}$ dia unit. Significant deformation of units, particularly in the wave-breaking zone, is observed due to migration of fill within the units. It has been estimated that deformations of at least 200-300mm occur in the wave-breaking zone. Containers orientated with their nose into the waves in the wave break zone showed some migration of sand from the nose and placement side onto the waves in the wave breaking zone is preferable. Containers placed side on to the waves showed no sign of instability and movement.

Of the 405 containers, about 30-40 have leaked and deflated to some extent due to a number of causes. Initially in accordance with recommended practice, the inlet and outlet trunks were designed to release air, but this was found to be a problem with slow sand leakage and was unnecessary if air was expelled from the containers prior to dropping. Divers tied off the leaking trunks and a robust method of sealing and securing the trunks was developed. However, further modifications were required after vandals cut some of the cords lacing the modified trunks. While the standard non-woven Terrafix geotextile has been more than adequate to resist surfboard fin cuts, boat anchors and spears have pierced a small number of containers. To improve durability a trial coating of urethane was used on 30 small bags on the top layer, but this proved to be a problem as about 15 of these bags have cracked and either partially or totally deflated. Further R\&D by Soil Filters Australia has resulted in a composite geotextile that abrasion resistance testing has shown to be very durable (Soil Filters Australia 2002). Containers using this composite material have been used for the Maroochy groyne, and to cover containers at Narrowneck where deflation has been excessive.

\section{Aerial Oblique Photography}

The oblique aerial photography has generally been carried out on an opportunistic basis by local professional aerial photographers when there is been good visibility of the 
reef [i.e. calm conditions with clear water]. The photos have provided a good qualitative assessment of marine growth, sand bar formations around and over the reef, infilling between units and any major damage to units. 
Table 1. Marine Species Identified at Narrowneck Reef

\begin{tabular}{|l|l|}
\hline $\begin{array}{c}\text { Benthos } \\
\text { kelp -narrow leaf }\end{array}$ & Nekton \\
kelp -broad leaf & Taylor \\
Cunjevoi & Bream \\
Feather star fish & Butter bream \\
barnacles & Whiting \\
Razor clam & Trevally \\
sea anenome & Cod (small groper) \\
sea urchin & Puffer fish \\
soft corals & Parrot fish \\
& Flathead \\
& Shovel nose shark \\
& Grey nurse shark \\
& Wobbegong \\
& Spotted eagle ray \\
& Common sting ray \\
& Crayfish - spotted (tropical rock lobster) \\
& Crayfish - blue \\
& Moray eel \\
& Wrasse \\
& Trumpet fish \\
& Trig \\
& Cardinal fish \\
& juvenile prawns \\
& Seahorse \\
& Bat fish \\
& Strippey \\
& Pike \\
& Tang \\
& Yellow fin mackerel \\
& turtle \\
\hline &
\end{tabular}

\section{Surf Parameter Observations}

Formal observations were commenced initially after completion of the reef but these have not been continued. However, a number of the project team visit the site with varying types of surf craft regularly and observations are logged. The breaker type is affected by crest height, tide level, wave height and wind speed/ direction.

It has been possible to evaluate the effect of crest height over a range of crest heights as the structure has settled and been topped up. With the crest at, or less than, the original "as constructed" height of $-0.5 \mathrm{~m}$ LWD [low water datum], a very hollow but hazardous wave develops that often sucks dry at the breakpoint. This type of wave is suitable only for the expert body board and short board riders. With the crest settled to lower than $-1.5 \mathrm{~m}$ LWD, waves [when they do break] tend to be spilling attracting long boards and surf skis. The target crest height has been reduced to a maximum of $1 \mathrm{~m}$ LWD for safety while still providing good surfing. The reef has been criticised for 
not creating the "perfect" surf but with the wide range of skill levels and surfcraft used, this is not practical (Jackson et al 2001). Surfing in the Narrowneck area, in rough order of popularity includes:-

- Body surfing

- Body boards

- Long boards (malibu) and mini-malibu

- Short boards

- Sailboards and kiteboards

- Surf skis, surf kayaks and paddle boards

In average conditions, the waves tend to be more spilling (Photo 5) than plunging particularly at high tide - this best suits long boards and is preferable for safety and more inexperienced surfers. However, in larger swells with offshore wind conditions the waves can be hollow (Photo 6) and the crest bags can "suck dry" even with the lowered crest level. In one very large long period swell, the reef attracted tow-in surfers. The reef tends to provide a surfable wave even with an onshore wind when the break on the adjacent natural sand bars is choppy and closing out. The video monitoring shows a very high percentage of times when waves break on the reef but not on the adjacent bars. Wave breaking has proven to be relatively insensitive to gaps left where containers have deflated and a perfect surface is not required.

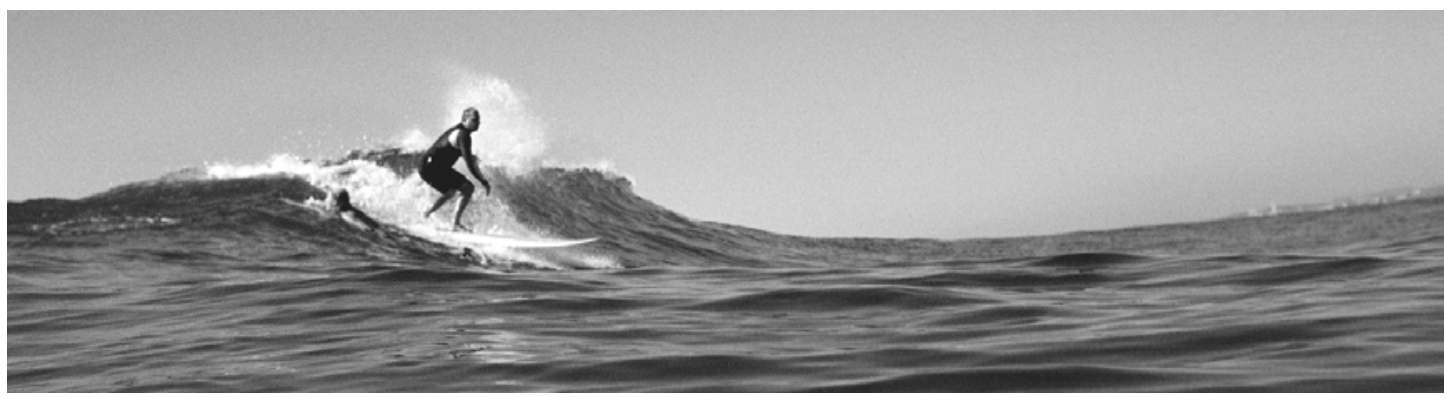

Photo 5. Spilling waves with swell under $1 \mathrm{~m}$

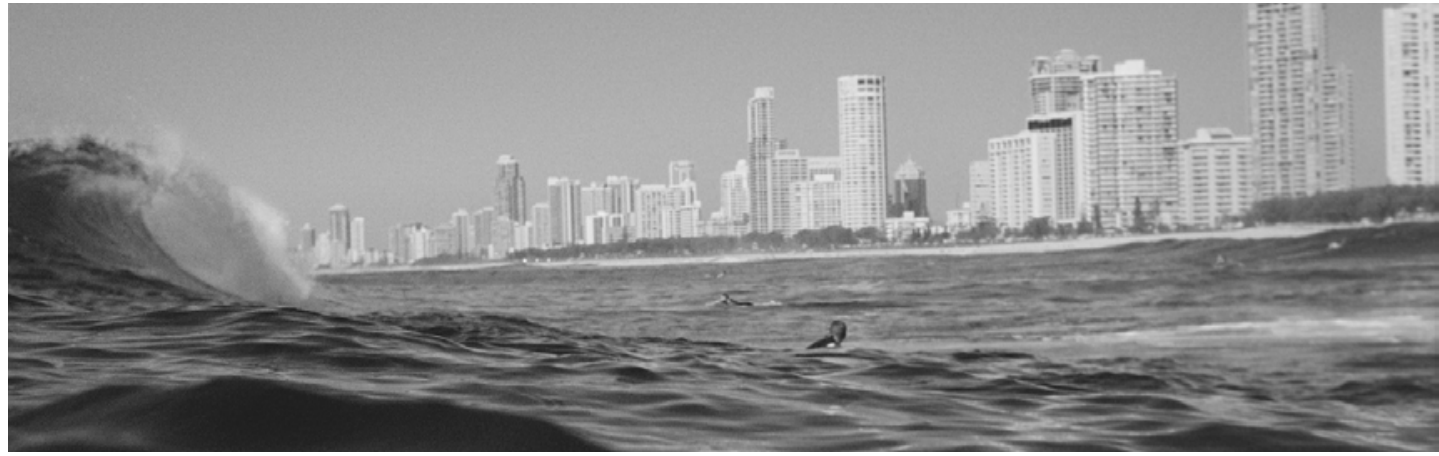

Photo 6. Hollow plunging wave with swell over $1.2 \mathrm{~m}$ 


\subsection{Pressure Measurements}

The sand containers appear to be hydraulically smooth with a low coefficient of reflection. As part of an undergraduate thesis (Corbett 2001) a trial container with pressure transducers on, and in it (Figure 2), was filled to approximately $80 \%$ capacity with sand similar to that used in the construction of the actual reef and sewn shut. The filled container weighed $696 \mathrm{~kg}$, was $1.5 \mathrm{~m}$ in length, $0.9 \mathrm{~m}$ in width and sat $0.5 \mathrm{~m}$ high.

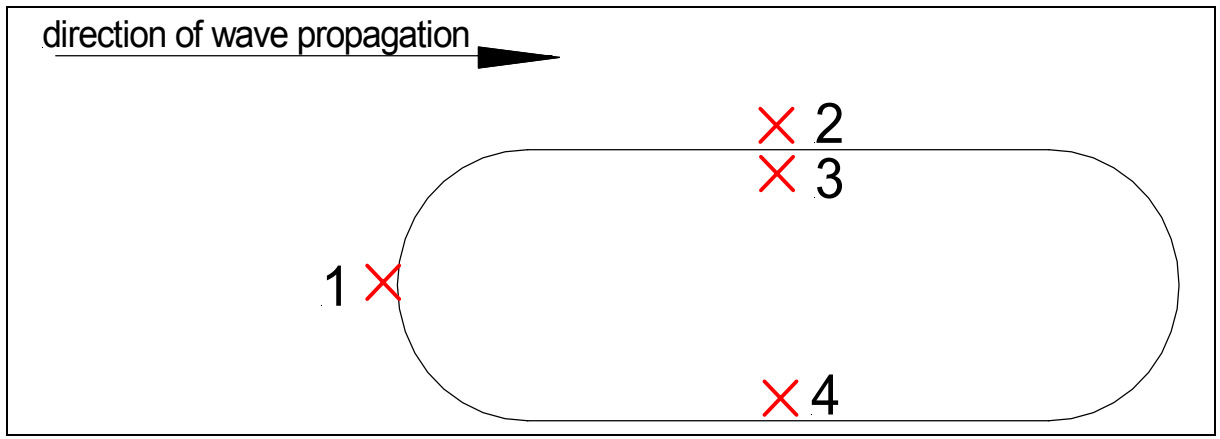

Figure 2. Location of pressure transducers

Corbett (2001) concluded that: -

(1) Attenuation of pressure fluctuations within the geotextile sand container is unhindered by the geotextile membrane, and is consistent with current theoretical models for wave-induced pressures in a horizontal seabed.

(2) Lag of the transmitted pressure wave was essentially insignificant.

(3) Due to the structure's response to wave-induced pressures, models developed for rubble mound breakwaters which assume that the structure is solid with respect to pressures should be used with caution

(4) Liquefaction, combined with horizontal differential pressures, provides a mechanism for the investigated failure mode.

(5) To control this mode of failure, appropriate filling and container shape is essential.

\section{CONCLUSIONS}

Numerical modelling alone is not able to provide a definitive design of reefs due to the complexity and the number of conflicting issues. The monitoring of the Narrowneck prototype has provided extensive "real world" data for modifications to the design. The $3^{\text {rd }}$ engineering redesign has now been completed. This redesign lowers the design crest height, further truncates the seaward slopes and infill the central channel. The central channel was originally needed with the shallow crest to reduce velocities. This design will be used when additional containers are placed in late 2002. In particular, a lower crest height is desirable for safety but has been shown not to significantly compromise erosion protection. The bathymetric surveys and video imaging show persistent salient and reduced erosion shoreward of the reef. The salient width has been compared with salients of natural reefs with similar crest depths and gross dimensions - very large or shallow reefs have not been considered. Previous investigations have used a wide range 
of natural submerged and partially emerged "reef" sizes, and this tends to over-estimate salient size for artificial reefs with a submerged crest for safety. This selected review using Narrowneck data has lead to a simple empirical formulae (International Coastal Management 2002).

The data collected from Narrowneck reef and the methodology developed (Figure 3) is being used in the design of the Palm Beach reefs programmed for commencement in 2003. An extensive monitoring program is proposed for this project to facilitate collection of data and modifications. Monitoring of Narrowneck reef has lead to the following general observations:-

- Reefs can provide both erosion protection and improved surfing but safety is a major issue.

- A 20-30m beach widening has been achieved even with significant storm events.

- A salient is persistent in the lee of the reef and erosion in storm events in the lee of the reef is reduced.

- A new diverse marine ecosystem has formed.

- Changes in the level of the structure have occurred but this has mainly been due to gross seabed changes.

- With the crest shallower than approximately $-1.0 \mathrm{~m}$ at low water, there are significant safety hazards to surfers.

- With the crest at approximately $-1.0 \mathrm{~m}$ at low water, there is still effective beach protection. [Flume modelling has showed that a reef constructed of permeable sand filled geotextile units with steps on seaward slope has significantly reduced wave height transmission compared to a smooth impermeable structure.]

- Even with a relatively low crest, the general surf quality is improved.

- There is good interlocking between containers and the container sizes used have been stable even when placed side on to the waves in the wave breaking zone.

\section{ACKNOWLEDGEMENTS}

Monitoring of this project has been undertaken in a cooperative approach by the following organisations:

- Gold Coast City Council (Principal)

- International Coastal Management (Project Engineers / Managers)

- Griffith Centre for Coastal Management (Co-coordinating Monitoring data and research)

- Soil Filters Australia Pty Ltd (Geotextile Contractor)

- McQuade Marine (Construction contractor)

- Water Research Laboratory (Research Centre at the University of NSW)

Data has also been provided from flume modelling done for Noosa Shire Council. 


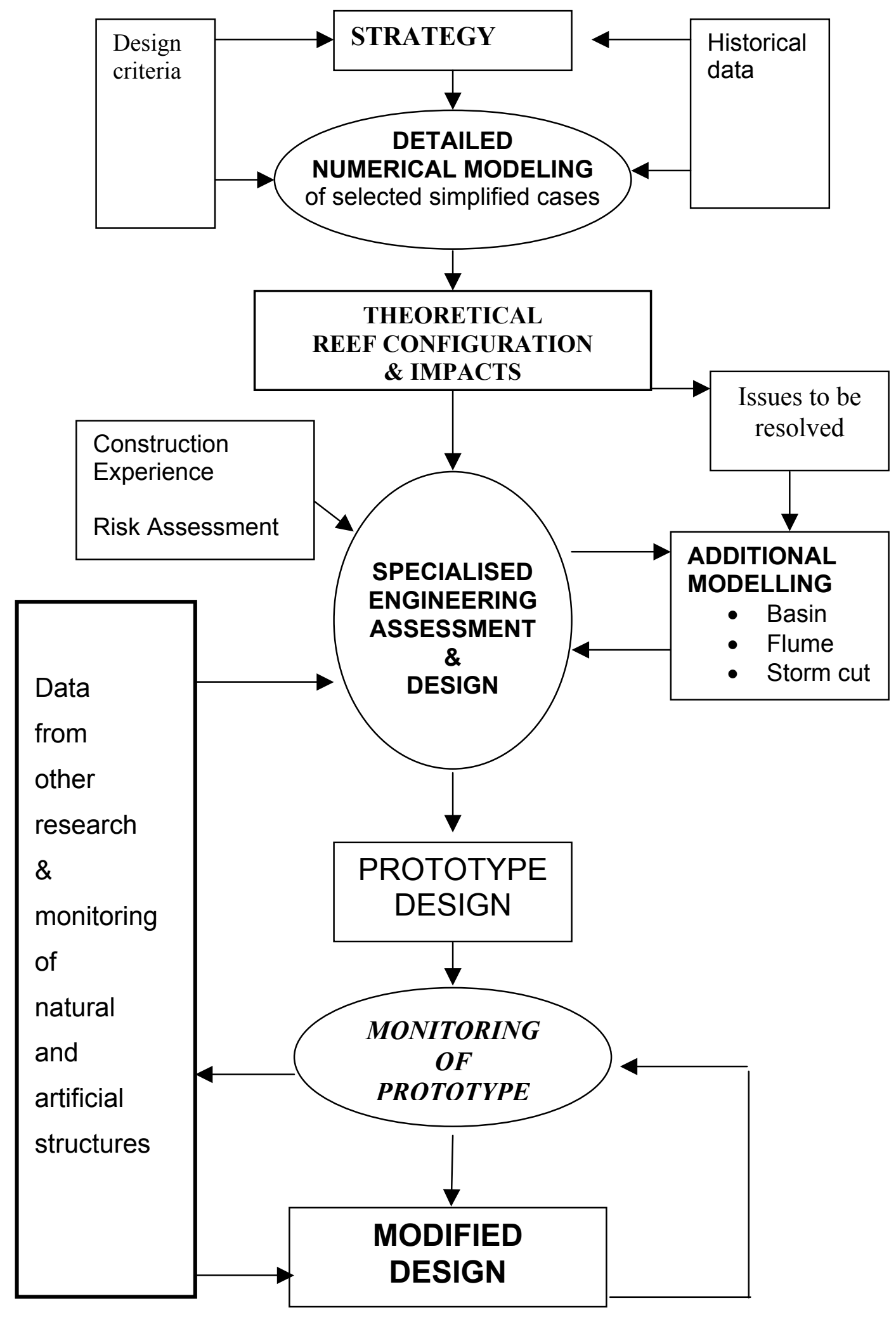


Proceedings of the $28^{\text {th }}$ International Conference on Coastal Engineering 7-12 $2^{\text {th }}$ July 2002 Cardiff, Wales

Figure 3. Reef design methodology

\section{REFERENCES}

Corbett, B.L., (2001) Wave-Induced Pressures and Internal Stability of Geotextile Sand Containers in Artificial Reefs. Final year Bachelor of Engineering Thesis, University of Queensland.

Jackson, L.A., McGrath, J., Tomlinson, R., (1997) Strategy for Protection of the Northern Gold Coast Beaches. Proceedings, $13^{\text {th }}$ Australasian Coastal and Ocean Engineering Conference, Vol 1 pp279-284

Jackson, L.A., Tomlinson, R., D'Agarta, M. (2001) Combining Surfing and Coastal Protection- What is the Perfect Surf. Proceedings, $15^{\text {th }}$ Australasian Coastal and Ocean Engineering Conference, pp 134-139

Holman, R.A., Sallenger, A.H., Lippman, T.C.D. and Haines, J.W., (1993). The Application of Video Image Processing to the Study of Nearshore Processes. Oceanography, Vol.6(3), 78-85.

International Coastal Management (1998) Summary of Impact Assessment Studies for the Northern Gold Coast Beach Protection Study. Report to Gold Coast City Council

International Coastal Management (2002) R\&D Report on Salient Calculations. Internal research and development report. Unpublished

Soil Filters Australia (2002) Report 027RD/03 - Geotextile Durability. Internal research and development report. Unpublished

Turner, I.L., Leyden, V.M.,Symonds, G., Cox, R.J., McGrath, J., Jackson, L.A., Jancar, T., Aarninkhof, S.G.J. and Elshoff, I., (2000). Predicted and Observed Coastline Changes at the Gold Coast Artificial Reef. Proceedings, International Conference on Coastal Engineering, ASCE, Vol.2, 1836-1847.

Walsh, A., Tomlinson, R., McGrath, J., Boak, L.and Jackson, L.A. (1999) Environmental Monitoring of the Northern Gold Coast Beach Protection Strategy. Proceedings, $14^{\text {th }}$ Australasian Coastal and Ocean Engineering Conference, Vol 1 pp708-713 
KEYWORDS - ICCE 2002

PREPARATION OF MANUSCRIPTS FOR THE PROCEEDINGS OF ICCE 2002

Jackson, Tomlinson, McGrath, and Turner

Beach nourishment

Breakwater

Erosion

Integrated coastal management

Monitoring

Reef

Surfing

Video 